\title{
Tensiones en torno al reconocimiento indígena \\ La lucha por ser mapuche y tehuelche en la costa $y$ valle de Chubut
}

\section{Valentina Stella}

\author{
Consejo Nacional de Investigaciones Científicas y Técnicas (CONICET) e Instituto de Investigaciones en \\ Diversidad Cultural y Procesos del Cambio (IIDyPCa), San Carlos de Bariloche. Río Negro. Argentina \\ ORCID iD: 0000-0003-0773-3891 \\ Correo electrónico: valenstella84@gmail.com
}

Recibido

abril de 2018

Aceptado

noviembre de 2018

doi: 10.34096/cas.i50.4340

\section{Resumen}

En el año 2009 comencé a trabajar junto con comunidades mapuche-tehuelche de la costa y valle de la provincia de Chubut. Durante aquellos años, muchas de las luchas y demandas giraron en torno a los sentidos locales de pertenencia y a la particularidad política que adquiere la doble adscripción como mapuche-tehuelche en esta región. La conformación de comunidades que se autoadscriben pertenecientes a estos dos pueblos es una de las características que definió el movimiento indígena en la provincia, y particularmente en la costa y el valle. El presente trabajo, por lo tanto, se centra en historizar aquel proceso de fortalecimiento y visibilidad de sus identidades para comprender las formas en que las personas mapuche-tehuelche fueron cambiando las condiciones que determinaban sus modos de aparecer en los espacios públicos y las formas en que fueron tomando conciencia de la responsabilidad política de ser los agentes de su propia historia.

\section{Tension over indigenous recognition: the struggle to be mapuche and tehuelche in the Chubut coast and valley}

\footnotetext{
Abstract

In 2009 I started working with the mapuche-tehuelche communities of the coast and valley of the province of Chubut. During those years, many of the struggles and demands revolved around the local senses of belonging and the political particularity acquired by the dual adscription as mapuche-tehuelche in this region. The formation of communities that self-describe as belonging to these two peoples is one of the characteristics that defined the indigenous movement in the province, and particularly in the coast and the valley. The present work, therefore, focuses on historicizing that process of strengthening and visibility of their identities, to understand the ways in which the mapuche-tehuelche people modified the conditions that determine their
}

\section{Palabras clave}

Mapuche-tehuelche; Luchas; Sentidos de pertenencia; Rótulos identitarios; Memoria

\section{Key words}

Mapuche-tehuelche; Struggle; Sense of belonging; Identity labels; Memory 
ways of appearing in public spaces and began to be aware of the political responsibility as agents of their own history.

\section{Tensões em volta ao reconhecimento indígena: a luta para ser ma- puche e tehuelche na costa e no vale da Província de Chubut}

\section{Resumo}

Em 2009 comecei a trabalhar em conjunto com as comunidades mapuche-tehuelche da costa e do vale da província de Chubut. Durante esses anos, muitas das lutas e demandas

Palavras-chave

Mapuche- tehuelche; Luta; Sentido de pertencimento: Rótulos de identidade; Memória giraram em volta dos sentidos locais de pertencimento e a particularidade da política adquirida pela dupla designação de mapuche-tehuelche nessa região. A conformação de comunidades pertencentes a esses dois povos é uma das características que definiram o movimento indígena na província, e particularmente na costa e no vale. O presente trabalho, portanto, centra-se em percorrer a história desse processo de fortalecimento e visibilidade das identidades, com o propósito de compreender as maneiras pelas quais o povo mapuche-tehuelche mudou as condições que determinaram suas formas de aparecer nos espaços públicos e as formas pelas quais eles tomaram consciência da responsabilidade política de ser agentes de sua própria história.

\section{Sobre el método y el campo: las lof mapuche-tehuelche de la cos- ta y valle de la provincia de Chubut}

Como resultado del trabajo de investigación en la localidad de Puerto Madryn (años 2009-2012), realicé mi tesis de licenciatura sobre las subjetividades políticas de los mapuche-tehuelche urbanos (Stella, 2014). Puesto que estas se encontraban atravesadas por los eventos, las relaciones sociales y los discursos que definen las alteridades en espacios nacionales (e internacionales), provinciales y municipales, fueron analizadas teniendo en cuenta todos estos niveles en sus reconfiguraciones hegemónicas en aquel contexto regional. Estos escenarios habían circunscripto al "indio permitido" (Hale, 2004) como un tehuelche - no mapuche y "casi extinto" - cuya legitimidad residía en las buenas relaciones mantenidas con los colonos galeses.

Fue en contraposición a esos presupuestos que, a fines del siglo $\mathrm{xx}$, comenzaron a emerger distintas iniciativas políticas que fueron desafiando las visibilidades imperantes desde el momento en que utilizaron la autodefinición "mapuche-tehuelche" para tensionar las formaciones provinciales de alteridad en las que ambos colectivos no podían ser parte de una misma subjetividad (Ramos y Delrio, 2005), y aún menos en contextos de ciudad. En la investigación doctoral (Stella, 2018) analicé los modos en que se relacionan las personas mapuche-tehuelche para conformar grupos como lugares de apego y como instalaciones estratégicas para la acción (Grossberg, 1992, 1996) en espacios urbanos y semiurbanos, con el fin de comprender las formas en que estos diversos proyectos políticos entraman redes más amplias de pertenencia y militancia.

La metodología utilizada a lo largo de estos años de investigación se centró, principalmente, en los enfoques etnográficos basados en los métodos cualitativos de producción de información original con especial énfasis en el trabajo de campo. Como parte de este último, he asistido a visitas guiadas en los museos, he estado entre el público en 
ciertos actos conmemorativos, en ceremonias, entre otros acontecimientos en los que participé y observé. En este camino, el enfoque etnográfico me llevó a descentrar mi investigación de la entrevista, entendida como un género convencional, para dar mayor importancia metodológica al evento comunicativo (Briggs, 1986). Esto es, a las formas - fueran o no las de la "entrevista" - que en cualquier intercambio producido con mis interlocutores pudimos negociar unos y otros para dar sentido a lo que queríamos contar, preguntar, responder, aclarar o negar. Estas situaciones me llevaron a confirmar la importancia de la reflexividad sobre mi presencia en el campo y a considerarla parte fundamental de la investigación. El momento metodológico o la situación etnográfica resultó en la vida real una relación en la que me comprendí mejor a mí misma y en la que pude entender el acontecer cotidiano desde perspectivas que antes no tenía, desde miradas que empezaron a estar atravesadas por las opiniones y percepciones del "Otro". Este "Otro", al momento de pensar ese mundo en el que transcurrían las cosas fue, desde el principio, un igual epistemológico, porque si yo era la antropóloga que estudió en la universidad, mis interlocutores/as eran los/as que producían, controlaban y transmitían sus conocimientos.

Las lof (comunidades) y organizaciones mapuche-tehuelche de la costa y valle de Chubut son el resultado de procesos particulares de formación de grupos que se caracterizan por la migración y el arribo de personas de distintos lugares de la provincia y de otras vecinas. En la década del noventa se inició un proceso de reemergencia de identificaciones indígenas ${ }^{1}$ urbanas con la conformación de cooperativas de artesanas y tejedoras mapuche, y de organizaciones y comunidades mapuche-tehuelche en la región. En la actualidad, y como consecuencia de estos procesos de reemergencia indígena ${ }^{2}$ en contexto de cuidad - en tanto son comunidades, organizaciones y familias que se configuran como grupo social y cultural diferente al interior del EstadoNación provincial-, podemos encontrar más de diez lof y organizaciones ubicadas en las localidades de Trelew, Rawson, Gaiman, Dolavon y Puerto Madryn.

En muchas de las conversaciones informales, entrevistas, actos públicos y participaciones más íntimas compartidas con cada uno de los grupos y personas durante mis trabajos de campo, solía aparecer como uno de los tópicos principales la lucha por los sentidos locales de pertenencia y la particularidad política que adquiere la doble adscripción como mapuche-tehuelche. El presente artículo, por lo tanto, busca historizar aquel proceso de fortalecimiento y de visibilidad de las identidades como mapuchetehuelche para comprender las formas en que las personas cambiaron las condiciones que determinaban sus modos de aparecer en los espacios públicos y las formas en que tomaron conciencia de la responsabilidad política de ser los agentes de su propia historia.

\section{"Están todos entreverados": la doble pertenencia en los procesos de lucha indígena}

Los efectos de poder que han tenido para las poblaciones indígenas los rótulos identitarios heredados de los estudios etnológicos (Harrington, 1944; Escalada, 1949; Casamiquela, 1987) han marcado y configurado el mapa de alteridad indígena en Chubut. A partir de esta herencia de los estudios clásicos de la etnohistoria, el discurso provincial reconocía como única alteridad oficial al "tehuelche" "autóctono" que se había extinguido como consecuencia, por un lado, de los contactos con el mapuche "venido de Chile" y, por el otro, por las campañas militares llevadas a cabo por el Estado argentino en el siglo XIX.

En este camino, las matrices provinciales de alteridad configuraron un escenario social y territorial en el cual no había un lugar habilitado para el reclamo indígena, puesto
1. Escolar (2007), Kropff (2008), Lazzari (2010), Rodríguez (2010), Ciccone y Hirsch (2011) y Bompadre (2013) son algunos de los trabajos que han abordado diferentes procesos que pueden denominarse como de reemergencias indígenas en la Argentina.

2. Algunos trabajos refieren a los procesos de reemergencia indígena como etnogénesis. Al separarse de algunas definiciones más clásicas del término (ver Bartolomé, 2003), estos trabajos utilizan etnogénesis para referirse a la configuración y visibilidad de identidades que son la expresión de procesos sociales de identificación étnica y reorganización de grupos que, desde el sentido común y estatal, se habían considerado como "extinguidos" o cuya existencia era impensable en una determinada región o espacio, por ejemplo, el urbano (Bartolomé, 2003; García y Valverde, 2007, entre otros). 
que, mientras los "tehuelches" habían desaparecido, los "mapuches" eran extranjeros. No obstante, estos mismos presupuestos comenzaron a ser cuestionados cuando la movilización indígena empezó, hace aproximadamente veinticinco años atrás, a poner en cuestión esas ausencias.

En primer lugar, dicha movilización revirtió aquel final premeditado sobre el mestizaje y la desaparición de los grupos hasta el punto en que Chubut pasó a ser una de las provincias con mayor cantidad de habitantes indígenas. En segundo lugar, motivó una escalada de solicitudes de reconocimiento de comunidades indígenas, que pasó del número de tres o cuatro personerías jurídicas otorgadas a principios de los noventa a más de doscientas en la actualidad. En tercer lugar, y lo que me interesa analizar acá, es que estos reclamos y reconocimientos fueron hechos en nombre de una doble pertenencia. La autoadscripción de organizaciones y comunidades como mapuchetehuelche terminó siendo una particularidad general del movimiento indígena de Chubut (Ramos y Delrio, 2005).

Esta doble adscripción puso en tensión el sentido común y académico para el cual solo era esperable una reemergencia de grupos étnicos en los términos de las autodefiniciones fijas y nítidas. Para la historia de antagonismos que había construido la provincia, no era posible que ambos pueblos formaran parte de una misma adscripción de pertenencia. En esta dirección, la doble pertenencia actualizó memorias silenciadas hasta entonces sobre procesos históricos ligados a experiencias de relocalización, de conformación de comunidades, de redefinición de parentescos y de alianzas políticas desde puntos de vista diferentes a los hegemónicos (Briones y Ramos, 2010).

$\mathrm{Al}$ reconstruir a sus familias o linajes como constituidos por antepasados mapuche y tehuelche, las personas evidenciaron trayectorias de grupo en que las alianzas y los procesos de familiarización (Ramos, 2010) fueron una forma política recurrente de proceder, particularmente en contextos críticos (Das, 1995) donde debieron enfrentar persecuciones de los ejércitos, cautiverio en campos de concentración, desmembramiento familiar, desalojos, desplazamientos forzados y migraciones, entre otras situaciones de avasallamiento.

La doble pertenencia - visibilizada en los procesos de lucha por ser reconocidos como pueblos indígenas preexistentes al Estado- puso en relieve una identificación particular; una en el que el "ser" era intrínsecamente el resultado de articulaciones políticas y parentales de larga data; $y$ en la que no había lugar para las fijezas ni para los criterios culturales más allá de la historia compartida y la memoria común (Ramos y Stella, 2017). Estos desplazamientos epistémicos - y las luchas epistémicas que inauguraronfueron el resultado de la movilización indígena en la provincia, un movimiento social heterogéneo en sus discursos, sus propuestas, sus posicionamientos y sus reconstrucciones del pasado, pero afín en el propósito de irrumpir en los discursos hegemónicos con nuevos pisos de interlocución acerca de "quiénes son" los indígenas de Chubut.

A partir de los aportes que Stuart Hall (2010) y Eduardo Restrepo (2004) hacen en relación con el multiculturalismo, sostengo que existen dos conceptos que se ponen en juego en aquellas tendencias gubernamentales que simulan la "admisión del otro". Por un lado, nos encontramos con los sentidos que giran en torno a la multiculturalidad. Actualmente, Chubut se presenta como una provincia que se reconoce como "pluricultural" (Stella, 2017); esto es el reconocimiento de la existencia en el territorio de aquellos sujetos sociales que conforman una heterogeneidad de horizontes culturales (Restrepo, 2004). Esta concepción en torno a "cultura" - entendida desde una perspectiva metacultural (Briones, 1998) - plantea una articulación asociada a un régimen de verdad que define una distinción de lo que es o no considerado cultural y que a su vez actúa como diacrítico cultural. Como lo señala Restrepo (2004), este régimen de 
verdad opera acorde con las relaciones de poder y de saber, enmarcadas en una lucha permanente por la hegemonía.

Por otro lado, nos encontramos con el multiculturalismo - o, en su defecto, pluriculturalismo, reconocido por la provincia de Chubut - que señala una serie de políticas que se despliegan en el plano del derecho. Estas tienen como fin apuntalar o no determinadas articulaciones de pluriculturalidad; por lo cual el pluriculturalismo se desarrolla en diferentes contextos y se articula de diferentes formas (Restrepo, 2004); lo que lo convierte en una política de Estado que plantea formas y proyectos que predican la "tolerancia" y la convivencia pluricultural (Briones, 1998).

Este pluriculturalismo o multiculturalismo en Chubut ha variado a lo largo de los años, pero siempre ha estado asociado a los rótulos clasificatorios heredados de los estudios etnológicos y entextualizados en narrativas locales. ${ }^{3}$ En su conjunción, estos últimos han influenciado las políticas públicas provinciales y municipales implementadas hacia los pueblos indígenas, así como a los distintos funcionarios y académicos locales al momento de discernir sobre la legitimidad o la ilegitimidad de los reclamos indígenas.

Así, por ejemplo, y enmarcado en un nuevo interjuego de clasificaciones, el gobierno provincial de los últimos años ha logrado reinstaurar la separación hegemónica entre "buenos" y "malos" indígenas, pero con sentidos renovados. El mapuche-tehuelche, leído hegemónicamente en clave tehuelche, ya no es el "indio folklórico" de un origen lejano de la argentinidad, sino un "descendiente" de aquel tehuelche, hoy "mestizado", que forma parte de un Estado que los reconoce dentro de su propia legibilidad: "ciudadanos argentinos". En contraposición, el mapuche-tehuelche, leído hegemónicamente en clave mapuche, ya no es el "indio" venido de Chile y ruralizado, sino un agente - siempre en sospecha- cuya forma de hacer política es vista como "terrorista", "delictiva", influenciada desde el extranjero y desde intereses foráneos. ${ }^{4}$ Los sentidos implícitos a esta distribución de valores son la asociación de lo tehuelche casi camuflado en el argentino común y de lo mapuche con un hacer conflictivo y separatista del Estado.

Este cambio en las matrices de inclusión y exclusión (Briones, 2005) de los gobiernos entrantes tanto a nivel provincial como nacional - a nivel provincial asumió el gobernador Mario Das Neves (2015-2017) y Mariano Arcioni (2017-2019), y a nivel nacional, el presidente Mauricio Macri (2015-2019)-implicaron un reposicionamiento del Estado en relación con los reclamos y demandas indígenas. El actual gobierno se presenta como un Estado que, garante de la propiedad privada, se ve obligado a reforzar el accionar de las fuerzas de seguridad (Escolar, 2017) con protocolos de procedimiento más autonómicos y de mayor despliegue numérico. No solo se desconocen los derechos provinciales, nacionales e internacionales de los pueblos originarios, sino que se han agudizado las relaciones de dominación y avasallamiento hacia ellos, en función de lo cual habilitaron discursos inéditos sobre "terrorismo" para justificar una política de represión y persecución a los indígenas, a las organizaciones y a los militantes que apoyen las causas y reclamos de estos pueblos en general. ${ }^{5}$ Bajo esta reconfiguración hegemónica, los mapuche pasaron a ser "los desestabilizadores de la soberanía nacional y de la democracia, los invasores y violentos chilenos"6 (Ramos, 2017, p. 1) que permanentemente traspasan la frontera nacional.

Frente a este panorama, el movimiento indígena cordillerano profundizó sus autoadscripción mapuche como ícono de su posicionamiento externo al Estado-Nación y para reforzar los sentidos de pueblo intercordillerano. En este último tiempo nos encontramos con cambios recientes y profundos en relación con las ideas que giran en torno al "ser mapuche". Por un lado, porque estamos frente a un Estado que ha llevado la "cuestión mapuche" a las esferas de los prejuicios y estereotipos del sentido común.
3. Coincido con Ana Ramos (2005) en que aquellas tendencias hacia la admisión de los "otros internos" —nombradas como multiculturalismo, pluriculturalismo o interculturalismo-, si bien han implicado un avance importante en materia de derechos humanos, con frecuencia también resultaron ser copias novedosas de modelos metaculturales ya conocidos.

4. Ver Diario Río Negro, 12 de enero de 2017, "Ministro de Chubut acusó a los mapuches del grupo RAM: son terroristas".

5. A modo de ejemplo, el Estado nacional, en complicidad con los gobiernos provinciales, ha sido el responsable de la privación ilegítima de la libertad del longko Facundo Jones Huala y de las muertes de Santiago Maldonado (joven que acompañaba la lucha de la recuperación territorial de la pu lof en resistencia en la provincia de Chubut) y de Rafael Nahuel (joven mapuche que se encontraba en un proceso de recuperación territorial de la Lof Lafken Winkul Mapu en la provincia de Río Negro).

6. Desde hace muchos años el movimiento mapuche en Chile es construido como un movimiento terrorista y separatista del Estado por los diferentes gobiernos. 
Por el otro, y en estrecha relación, porque se ha instalado la convicción general de que los mapuche representan al enemigo interno por excelencia.

En la comarca de la costa y valle de Chubut la situación es otra. Si bien las comunidades de la región han acompañado muchas de las luchas encaradas en la zona de la cordillera y se han pronunciado, sobre todo en el último tiempo, en contra del Estado que ha instaurado un contexto de persecución y represión hacia los indígenas, muchas de las organizaciones y comunidades de esta zona han venido enmarcando sus luchas desde otro lugar. Uno que busca poner en valor la doble pertenencia y visibiliza tanto las memorias y los saberes del pueblo günün a künä (o tehuelche) junto con los del pueblo mapunche (o mapuche).

El sentimiento y los sentidos políticos que adquiere en esta región la doble pertenencia responden menos a las lógicas oficiales de clasificación —basadas en una etnología racializada extemporánea- que a las memorias donde se conjugan los recuerdos de los/las abuelos/as, las experiencias de levantar un nguillatun (ceremonia), la ancestralización colectiva y las experiencias situadas de lucha. En este camino, los grupos que empezaron a militar en torno a sus saberes mapuche-tehuelche fueron siendo agentes activos en la selección de evidencias históricas, particularmente al hacer sus propias elecciones políticas-afectivas en sus usos de las memorias y de los documentos disponibles.

La dialéctica entre procesos hegemónicos de clasificación (alterización) y experiencias de conocimiento ancladas en los antepasados (memoria) promovió procesos de subjetivación política en los que confluyen viejas categorías de la antropología con sentidos afectivos y creativos de identidad. La información disponible —en libros, documentos y narrativas oficiales- es incluida, junto con los relatos heredados de sus antepasados, en el conjunto de fuentes con las que es posible restaurar "lo que verdaderamente sucedió en el pasado". Pero estas "fuentes" - necesarias para reconstruir lagunas, silencios y revertir los "no-saberes" (Nahuelquir, Sabatella y Stella, 2011) — son leídas desde lugares de apego y desde marcos afectivos de ver y entender el mundo. De acuerdo con Joanne Rapapport (2005), para comprender los sentidos sociales de una documentación escrita, no solo basta describir sus contextos de producción, sino también cómo esta ha sido leída a lo largo del tiempo y a través de las fronteras culturales.

El hecho de habilitar un lugar político de participación pública como pueblo mapuche-tehuelche es un posicionamiento disruptivo, puesto que este pone en cuestión las matrices hegemónicas con las que se ha incluido o excluido históricamente al indígena en Chubut. El tehuelche ha sido representado oficialmente como "indio bueno" en la medida en que su lugar de enunciación permaneciera más cerca de las manifestaciones "folklóricas" - actos rememorativos, lengua y prácticas culturales que son "toleradas" por el multiculturalismo provincial—, que de aquellas catalogadas como "políticas" -reclamos y demandas por incumplimiento de derechos y recuperaciones territoriales, por ejemplo-. Para la mirada oficial, el tehuelche históricamente ha sido un sujeto del pasado o una presencia "despolitizada" por excelencia.

Además de enfrentar los efectos coactivos de esta idealización (Alonso, 1994) del tehuelche, la movilización indígena en la costa y valle - conformada mayormente por organizaciones y comunidades urbanas - ha tenido que pelear su visibilidad como sujetos de derecho frente a discursos dominantes en los que el indígena era aquel que vivía en comunidades rurales. Ante este desafío, las exposiciones y las intervenciones culturales en distintas instituciones - charlas sobre conocimiento indígena en las escuelas, por ejemplo- fueron sus sitios habituales de circulación. El control sobre sus vidas cotidianas y la lucha por cambiar sus condiciones de vida estuvieron centrados en una vigilancia epistémica, lo que habilitó lugares hasta ese momento inexistentes 
para definirse como los productores autorizados de los conocimientos indígenas. En esta dirección, entiendo que los nuevos lugares de enunciación en los que el pueblo günün a künä adquiere un emergente primer plano constituyen una profundización de los procesos de toma de control, en una provincia donde los discursos multiculturales en torno al "tehuelche" siempre fueron entextualizados, autorizados y circulados desde el poder.

Destaco dos procesos de lucha particulares que se desarrollaron en los últimos años en torno a las pertenencias étnicas y sus puestas en valor como pueblo mapuche-tehuelche en la costa y valle. Uno tiene que ver con la lucha por el acceso al pasado y el control de sus usos. El otro, y en relación con el anterior, tiene que ver con el empoderamiento del indígena urbano en la producción y transmisión de esos saberes y conocimientos. Ambos procesos han logrado que la visibilización de una doble pertenencia indígena ya no pueda ser interpretada meramente como una simple reproducción de los discursos oficiales multiculturales ni como una mera apropiación de los lugares disponibles por la hegemonía provincial. Por el contrario, señalan un camino sumamente afectivo de resistencia que ha definido y ha caracterizado muchas de las agendas políticas y lenguajes de oposición al poder que se han desarrollado en esta región.

\title{
Mayor control en los usos del pasado
}

\begin{abstract}
Hubo un sincretismo religioso y lo tehuelche se mapuchizó. Pero el mapuche como pueblo estaba del otro lado de la cordillera. Hoy hay descendientes vivos de grandes caciques tehuelches. Solo son algunas familias, los otros son descendientes de mapuches. Los Ñanco, por ejemplo, son descendientes de Sacamata, uno de los caciques más serios del norte de la Patagonia, nacido entre 1870 y 1880 [...]. El 99 por ciento de los que se definen como mapuches son de origen tehuelche. Pero se han dado muchas confusiones por la lengua o el apellido. Así se va perdiendo la identidad. [...] Los nietos de mis maestros, que sabían lo que eran, hoy son todos mapuches. Es decir, el abuelo es tehuelche puro, pero el nieto es mapuche. [...] La lengua tehuelche es una lengua muerta. Murió en 1960. Y no hay interesados en aprenderla. Yo lo hice porque era consciente de que mi maestro, José María Cual, era uno de los últimos que la hablaba [...]. Hoy se pierde la cultura. (Hanglin, R. Diario La Nación, 16 de septiembre de 2014)
\end{abstract}

Como se desprende de este relato, la construcción hegemónica de la imagen del tehuelche y del mapuche ha escondido otras tramas y otras relaciones de dominación dentro de las cuales ciertos académicos y el Estado parecerían ser los únicos autorizados para narrar la historia, las relaciones entre ambos pueblos; para contar sobre sus conocimientos, sus prácticas y hasta sobre sus memorias.

Al construir al "tehuelche" como extinguido, y a su cultura como una expresión que se desarrolló en un tiempo pasado, quienes ocuparon por muchos años el lugar social de la ciencia social en Patagonia se han presentado como la única voz "experta" para hablar sobre este pueblo. De este modo, se estableció una relación de subordinación a partir de la cual las familias indígenas de la región —-como "los Nanco" de la comunidad Pu Fotum Mapu de Puerto Madryn a la que hace referencia la cita anterior- parecerían haber quedado con poco margen para contarse y pensarse a sí mismos en el presente. Este escenario multicultural de visibilización controlado por la hegemonía académica y estatal fue el contexto a partir del cual se han enmarcado las luchas de los mapuchetehuelche de la región. Luchas que no solo han buscado revertir estos dispositivos separatistas y clasificatorios, sino que, además, han buscado tener mayor control en los usos de un pasado que les fue arrebatado. 
7. En la tesis de licenciatura (Stella, 2014) hago un análisis detallado sobre el acto y sus implicancias, tanto en la construcción de una narrativa hegemónica que configuró las alteridades de la provincia, como también las significaciones en las luchas y en los procesos de subjetividad como mapuchetehuelche para la comunidad.
Cuando iniciaba mi proceso de investigación, recuerdo que las primeras búsquedas de información sobre comunidades mapuche-tehuelche en la localidad de Puerto Madryn referían, en su mayoría, a las actividades que estas comunidades realizaban en el marco del aniversario de la ciudad. Las noticias de los diarios, los portales u otros sitios informativos remarcaban la participación de una comunidad mapuche-tehuelche en el acto rememorativo de la llegada de los "galeses" a la costa de la ciudad, y su posterior encuentro armonioso con "los tehuelches". Esta recreación simbólica continúa hasta el día de hoy representando el hito fundacional de la ciudad, y de la provincia en general, hito a partir del cual se resaltan como ejemplares "las buenas relaciones de convivencia" entre estos dos pueblos. ${ }^{7}$

En aquel entonces, me preguntaba por qué las mismas comunidades participaban de un acto que en el fondo parecía consolidar la imagen de que los únicos habitantes originarios habían sido los tehuelche ya extinguidos - y no así "los mapuches invasores"-, y que únicamente figuraban en la historia oficial por haber establecido relaciones pacíficas y de cooperación con los colonos galeses - quienes son resaltados por traer "el progreso" a la zona-. Parafraseando a Joanne Rapapport (2005), me preguntaba cuál era la razón por la cual los mapuche-tehuelche encontraban en determinadas prácticas, diacríticos y narrativas reproducidas por cierto sector de la academia y el relato oficial los lugares para poder reafirmar su identidad.

Estas preguntas encontraron sus respuestas al conocer y conversar con los integrantes de las lof, al escuchar sus trayectorias y sus motivaciones, y al hecho mismo de poder participar de sus actividades. Entendí que las experiencias de los mapuche-tehuelche de esta región deben interpretarse dentro de los marcos de configuración estatal (Rapapport, 2005). Ya que son estos mismos marcos los que habilitaron los lugares para la visibilidad indígena en un contexto en el que, años anteriores, esto parecía imposible. Fueron esos mismos lugares de reconocimiento oficial multicultural los que permitieron que comenzaran a formar parte de una narrativa que históricamente los invisibilizó y estigmatizó. Como lo expresaba una de las jóvenes de la comunidad:

Y para mí, ahora participo como diciendo 'iacá estamos!' Por el reconocimiento y porque hemos ganado el lugar hace un par de años. Y que la gente de Madryn sepa. ¿Y si no, qué parte van a ver? Que llegaron los galeses, fundaron la ciudad y ahora estamos acá gracias a ellos. (Entrevista personal S. Ñ., febrero 2010)

Frente a un contexto de configuración de alteridades, atravesado por una historia de opresión, discriminación y por un genocidio (Delrio, 2010) que ha dejado a quienes se reconocen como indígenas con poco margen de maniobra para la reconstrucción de pertenencias y memorias de su pueblo, las personas y familias de la región se han encontrado con la dificultad para entramar relaciones con su pasado como mapuchetehuelche, y aún más en contextos de ciudad.

A la estigmatización, a los silencios obligados y a los olvidos forzados impuestos por los dispositivos de control estatal —escuela, gendarmería e iglesia, entre otros- se le sumaron los discursos de ciertos académicos y naturistas cuyos trabajos han atravesado fuertemente el sentido común y han logrado imponer formas legítimas e ilegítimas de "ser indígena" en Chubut.

Como lo vimos en la cita al inicio del apartado, las declaraciones de ciertos académicos y comunicadores han reproducido el imaginario popular que sostiene que el tehuelche habría sido el único pueblo originario en habitar el territorio "argentino" pero que desapareció por un paulatino proceso de aculturación con el pueblo mapuche, el cual llegó - como invasor - del otro lado de la cordillera, territorio "chileno". Estas declaraciones tienen más peso aún en la costa y valle, zona en la que viven muchas de las 
familias a las que la cita hace referencia, y contribuyen a aquel discurso oficial sobre la inautenticidad de "lo indígena" y, en consecuencia, a la deslegitimación de cualquier reclamo proveniente de estos colectivos. Así, ciertos académicos podían interpelar al longko de la lof Pu fotum mapu como tehuelche ("Los Ñanco [...] son descendientes de Sacamata, uno de los caciques más serios del norte de la Patagonia" (Hanglin, R., Diario La Nación, 16 de septiembre de 2014) pero no así como mapuche; poniendo en duda sus pertenencias y autoidentificaciones: "los nietos de mis maestros, que sabían lo que eran, hoy son todos mapuches. Es decir, el abuelo es tehuelche puro, pero el nieto es mapuche" (Hanglin, R., Diario La Nación, 16 de septiembre de 2014).

El poder performativo de estos discursos se hace presente por medio de estereotipos y relatos que constantemente deslegitiman las demandas y reclamos de los mapuchetehuelche. Como le sucedió a uno de los integrantes de la lof Newentuaiñ inchiñ también de Puerto Madryn - al iniciar un proceso de recuperación territorial en el año 2006. Este territorio es un chenque - enterratorio humano- que se encuentra ubicado en el casco céntrico de la ciudad. En aquel entonces, y frente al pedido y reclamo por la posesión comunitaria del espacio considerado sagrado y ancestral, la municipalidad de la localidad rechazó tal solicitud al argumentar que el "demandante" "era mapuche de origen transandino", y no tehuelche de "origen argentino". Por lo cual, aquella solicitud no tenía lugar, debido a que los restos allí encontrados pertenecerían al segundo grupo por considerarlos como el verdadero pueblo que habitó en la región. Para la municipalidad, los restos humanos allí encontrados no pertenecían a ninguna comunidad indígena debido a que no había un criterio de "consanguinidad" que avalara esa conexión.

A este primer argumento se le sumó otro. Los agentes municipales manifestaron que "la zona entera" era parte del "medio ambiente" que el pueblo "tehuelche" utilizó —en tiempo pasado- para desarrollar "su cultura". Pero — continúa el argumento oficial—, como consecuencia del inevitable progreso y de su extinción, aquel territorio ya no pertenecería a tal pueblo, sino que era parte de la jurisdicción provincial y estatal argentina. Por lo cual el reclamo, además de no tener lugar, era "ilógico": era "como querer declarar 'lugar sagrado' al cementerio municipal" (Carta del Consejo Municipal leída por L.A. en contexto de entrevista, junio 2010).

Como se desprende del análisis de tales argumentos, la imagen del indígena oficial en la región estaba atravesada por tres criterios hegemónicos bien definidos: que el único habitante de la región fue el tehuelche ya extinguido y que, si existiera, no podría estar en un contexto urbano. Y que el mapuche es de origen trasandino o extranjero, por ende, está inhabilitado para reclamar.

Sin embargo, las comunidades pudieron revertir estos lugares de invisibilización, estigmatización y obturación de cualquier pertenencia como indígena en la ciudad al mostrar su capacidad de agencia para transformarse en los propios narradores de su historia. En este camino de empoderamiento, los mapuche-tehuelche han hecho uso de la evidencia histórica - aquella que se desprende de los estudios académicos y de aquellos primeros exploradores (Cox, 1863; Falkner y Musters, 1911, entre otros) - no solo para acceder al control sobre las formas de narrar el pasado y volver a ser protagonistas de su curso, sino para denunciar una historia más larga de opresión. Como lo señalaba un joven: "Fuimos borrados de la historia porque había que tapar el objetivo de apropiarse de nuestras tierras. [...] Sin embargo, quedan documentos que pueden dar cuenta de lo que verdaderamente pasó" (Huircapan, D., Agencia Paco Urondo, 7 de julio de 2015).

Frente a aquellas interpelaciones hegemónicas que señalaban la "muerte" de la lengua tehuelche - con el fallecimiento del "último hablante" -, la "mapuchización", el 
mestizaje, la aculturación de las familias indígenas y, en consecuencia, el proceso casi inevitable de "extinción de la identidad", los mapuche-tehuelche, primero, debieron demostrar su existencia, y luego, pelear por su derecho a entramar, de formas novedosas para la provincia pero afectivas para ellos, sus pertenencias y conexiones con el pasado. En aquel contexto y en esa condición de subalternidad que les impedía, incluso, contarse a sí mismos y decidir sus destinos identitarios, las familias indígenas se han valido de la misma academia para mostrar públicamente su legitimidad como demandantes de derechos.

El objetivo de recuperar el control sobre ciertos usos del pasado se inició necesariamente con la construcción pública de sí mismos como enunciadores privilegiados de su pasado. En esta dirección, prácticas recurrentes como las de usar quillangos (manto de piel) en eventos públicos o narrar historias como "leyendas tehuelches" en actos oficiales - entre otras prácticas entendidas hegemónicamente como "folklóricas" y aceptadas por la lógica del multiculturalismo- se han vuelto instalaciones estratégicas para habilitar sus propias agencias en contextos de invisibilización indígena.

Aquí también coincido con Joanne Rapapport (2005), quien señala que la historicidad de los objetos, los lugares, los relatos y los documentos se reactiva en una diversidad de formas, y que esta heterogeneidad evidencia la potencialidad de las personas para producir historia. Si bien las condiciones para la producción y circulación de una "historia verdadera" siguen siendo distribuidas de modos asimétricos entre los indígenas y los académicos - entendidos aquí como lugares de enunciación-, los mapuche-tehuelche han sorteado esta jerarquía haciendo uso tanto de la historia oficial como de la memoria oral para ser actores principales de sus destinos. Los restos de sus antepasados, las ngtram (historias antiguas), los nglam (consejos) y las memorias heredadas de los padres, madres y abuelos/as han sido fundamentales para reinterpretar su pasado y producir nuevos y diferentes horizontes de legibilidad. Contrariamente a lo que vaticinaban algunos científicos- "la pérdida de la identidad" (Hanglin, R., Diario La Nación, 16 de septiembre de 2014) -, estos horizontes han hecho que hoy en día sea impensable esta región sin la presencia y la voz del pueblo mapuche-tehuelche en sus tierras.

El proyecto restaurador inicia con la construcción de un lugar legítimo - e incluso privilegiado- de quienes se reconocen como indígenas para habilitarse a sí mismos como los enunciadores más autorizados para narrar su pasado. Por eso, las primeras tareas colectivas se centraron en dar cuenta de su condición exclusiva como herederos de los conocimientos y memorias que fueron silenciados oficialmente. Por un lado, la memoria oral heredada y transmitida reafirma que los procesos de comunalización fueron un lugar de apego y una forma de lucha frente al avasallamiento de un Estado que irrumpió en la vida cotidiana de los indígenas, desmembrando familias, grupos, relaciones y formas de ser y entender el mundo. Por el otro, la memoria oral, acompañada de las fuentes escritas o de las relecturas en colaboración con investigaciones académicas (Rapapport, 2007; Rodríguez, 2010; Leyva y Speed, 2015; entre otros) devino la prueba irrefutable de una historia de relacionalidad entre los pueblos mapuche $\mathrm{y}$ tehuelche y de su doble pertenencia en el presente.

Desde este lugar de enunciación, por ejemplo, los recuerdos de una abuela referente de la región subrayan la fuerza performativa de las ceremonias y de los procesos de familiarización indígena para refundar el pasado y restaurar las memorias en contextos de avasallamiento. Así lo recordaba:

Mi mamá y mi papá eran tehuelches, yo no tengo la parte de mapuche, nada más que enseño mapuche. [...] Y después mi papá y mi mamá no sé por qué dejaron de hablar y empezaron hablar mapuche. Cuando mi abuela falleció ya no hablaron 
más en tehuelche. Es como que lo dejaron, ¿viste? Y así fueron hablando todos, los Cuales, todos, los abuelitos Cuales esos hablaban en tehuelche y no hablaron más, hablaron en mapuche. El único que siguió hablando hasta que murió fue el abuelo José María Cual, ese sí, pero ese estaba en el pueblo. Allá tehuelches son los Chiquichano, los Cuales y los Yanquetruz, todos son mi familia esos, pero familia lejana. Eso ya están todos entreverados, por ahí la madre es mapuche y el padre era tehuelche, están cruzados. ( Entrevista personal con M. T., noviembre 2015)

$\mathrm{Al}$ recordar a los/as ancianos/as mapuche y tehuelche, y al presentarse ella misma como tehuelche pero hablando en mapuche, esta abuela señala que las identidades, los usos de la lengua y las prácticas de los grupos y las personas no son algo estático y cerrado, sino, por el contrario, el resultado de procesos dinámicos y cambiantes. Contrariamente a lo que plantea la cita al inicio del apartado - un pueblo imponiéndose sobre otro hasta lograr su "desaparición" - esta abuela resalta el modo en que las familias fueron conectándose por medio de la lengua y de las ceremonias, entramando relaciones y afectos para sobrevivir en un contexto de dominación estatal que se proponía "eliminar" su identidad:

Mi abuela se llamaba Piñocash. Cuando le hicieron los documentos, cuando ya le empezaron hacer los documentos le cambiaron los nombres, le pusieron Manuela Velázquez, nada que ver. Mi papá se llamaba Huenufilu, nombre solamente. En vez de ponerle después el apellido siquiera. No, nada, nada para que ellos fueran a decir que ellos son. Antes, a la gente mapuche y tehuelche la tenían como animales. La ponían, le ponían como ponerle una marca. A vos te gusta una marca y la marca que te guste y así hacían. Así le fueron cambiando los nombres, todo. (Entrevista personal M. T., noviembre 2015)

La memoria oral transmitida entre generaciones no solo permite reconstruir afectivamente las pertenencias como mapuche-tehuelche, sino también denunciar las agencias estatales como las únicas responsables del avasallamiento del indígena -en contraposición a una historia en la que esta responsabilidad es adjudicada a los "mapuche invasores". Para los mapuche-tehuelche, los académicos y los funcionarios del Estado habían acusado sin evidencia histórica a los mismos indígenas de la "pérdida de su identidad". Sin embargo, el trabajo colectivo de reconstruir sus memorias mostró que los olvidos forzados y la concepción hegemónica sobre "aculturación" son el resultado histórico del despojo territorial y la imposición de dejar los campos, del cambio de los nombres, de la prohibición de sus ceremonias y de la lengua por parte de un Estado genocida.

El uso de la memoria oral -incluso cuando sus relatos presuponen los argumentos oficiales en algunas de sus interpretaciones-empezó a ser considerado como una de las principales herramientas para legitimar una posición más valorada de sí mismos en la historia y, simultáneamente, para denunciar la opresión a la que han estado sometidos los mapuche y los tehuelche por igual a lo largo de los años. Hacer uso de sus propios pasados heredados les permite posicionarse públicamente como un pueblo ancestral que está vivo y "en lucha" en la actualidad.

Por lo tanto, las comunidades de la región han apelado tanto a la narrativa histórica oficial como a la memoria oral para poder sobrevivir a la violencia estatal. Como consecuencia, las familias han sorteado algunas de las condiciones de su desigualdad y accedieron al control sobre los usos de su pasado. Un control que es entendido como fundamental para encarar un proyecto político hacia el futuro. $Y$, en este proyecto político, encarnar en sus propios cuerpos la continuidad de un pasado tehuelche fue el camino elegido para apropiarse de la legitimidad enunciativa que, en la provincia y en la región, había sido negada. El ser tehuelche complementa los sentidos de pertenencia 
8. La puesta en valor de agencias y prácticas desde propias epistemologías y ontologías indígenas, así como el aporte a los estudios desde una ciencia más reflexiva, comprometida y descolonizadora, vienen siendo trabajados por varios autores (Walsh, 2007;

Escobar, 2007; Quijano, 2011; Krotz, 2018, entre otros). al pueblo mapuche y subraya en particular el derecho a ser ellos mismos los más autorizados para reconstruir el pasado en aquel territorio.

\section{Mayor control en la producción y transmisión del conocimiento}

En estrecha relación con el objetivo político de controlar las narrativas de su devenir histórico, otro de los proyectos encarados por los mapuche-tehuelche para "proyectarse hacia adelante" es aquel relacionado con el control sobre la producción y transmisión de sus conocimientos y saberes.

Como aclaramos anteriormente, aquellos conocimientos en torno al pueblo "tehuelche" estuvieron, mayoritariamente, en manos de ciertos académicos que se han arrogado el control sobre los mismos al argumentar la supuesta "mapuchización" y la posterior "desaparición" de la identidad y la cultura. No obstante, las comunidades buscan revertir - mediante una trayectoria y un proyecto descolonizador- la invisibilización y subordinación a la que han estado sometidas, al presentarse como los productores y transmisores de saberes considerados ancestrales, y al volver a habitar y entender el mundo desde sus propios marcos de interpretación. ${ }^{8}$

En este camino, algunas abuelas de la región vienen llevando a cabo un proyecto de revitalización y enseñanza de la lengua en escuelas con modalidad de educación intercultural bilingüe o en talleres particulares. Aquellas instancias de fortalecimiento y aprendizaje del mapudungun se han tornado lugares de lucha cuya importancia se ha vuelto fundamental en estos últimos años y en estos contextos de ciudad. El habla es aquel lugar que les permite tener acceso a los marcos mapuche-tehuelche de interpretación. En ellos, los significados de los nombres y apellidos, los ngtram, los nglam, los epew (cuentos), los tayil (cantos), entre otros eventos de habla, son puestos en valor por su fuerza performativa para entramar relaciones y reconstruir las memorias que les permiten refundar el pasado y pensarse como parte de un pueblo que se proyecta a futuro.

Coincido con Lucía Golluscio (2006) en que la lengua vernácula cumple un rol fundamental, tanto en la constitución de las identidades de las personas, como en la comunalización de sus vínculos. En contraposición a aquellos argumentos que instalaron la idea de "muerte" de la lengua, las abuelas que vienen enseñando y transmitiendo el idioma no solo han demostrado que está "vivo", sino que han mostrado la capacidad de controlar y resguardar sus saberes y conocimientos en contextos de avasallamiento y de olvido forzado. La posibilidad de poder enseñar el mapudungun y todo lo relacionado con él es una de las prácticas descolonizadoras más valoradas por los mapuchetehuelche de la zona, con vistas al empoderamiento colectivo y a la toma de control sobre las formas socioculturalmente significativas de transmitir sus conocimientos del mundo. De este modo lo entendía una de las abuelas:

Yo enseño canciones para los chicos, enseño a hablar, a cantar. Entonces yo cuando empecé a enseñar la lengua me hice un kultrun. Lo hice de plástico, porque no puedo hacer de madera porque el de madera es de la ceremonia, antiguamente era de la ceremonia. Tengo mucho respeto a eso, entonces cuando empecé a enseñar dije 'hago el kultrun de plástico, para enseñar'. Entonces esa gente viene a aprender acá, ya saben. Esa fue la cultura, la cultura de antes, la van aprender bien, no lo aprendan así cualquiera. (Entrevista personal M. T., noviembre 2015)

El "respeto", "la cultura de antes", el "aprender bien" son todos mandatos y enseñanzas que esta abuela transmite a la hora de enseñar la lengua. La enseñanza del mapudungun 
va mucho más allá del mero significado de las palabras. Es la transmisión misma de las formas de habitar y entender el mundo como mapuche.

La enseñanza de la lengua no es la única forma posible de transmisión de conocimiento. Otro de los caminos para producir y transmitir ciertos saberes es aquel relacionado con el posicionamiento político a partir del cual las comunidades se presentan como sujetos "en lucha". Es decir, aquellos lugares disponibles por la hegemonía que les permiten visibilizarse y contarse públicamente ya no como "objetos de estudio del pasado" sino como "protagonistas de su propia historia".

En una de las primeras conversaciones que mantuve con las jóvenes de la comunidad $P u$ Fotum Mapu me contaban que, cuando ellas iban a la escuela, el tema sobre "los indígenas" era tratado por los docentes por medio de determinados manuales escolares. En aquel contexto, las jóvenes se encontraban con la obligación de tener que refutar ciertas definiciones que los presentaban como un pueblo extinguido o relegado a la zona rural. El hecho de formar parte de una comunidad que había comenzado un proceso de lucha y reemergencia indígena en la ciudad les permitió empoderarse de manera tal que lograron tomar el control sobre las formas en que en el aula se narraban la historia y los conocimientos en torno su pueblo. Así me lo relataron:

Cada vez que salía el tema indígena yo saltaba a opinar o a hablar. Quizá no sabía tanto, pero la historia te sirve para saber qué es lo que pasó con tu pueblo, por qué hoy te vestís con esta ropa y hablás este idioma, por qué compañeros que son de mi misma cultura creen en otra cosa. $Y$ entonces, saber el significado de tu apellido o saber aunque sea un poco de la historia de tu pueblo, eso ya te ayuda a defenderte. Genera respeto y educación. Al investigar pude tener armas para defenderme del resto, que también aprende a conocer. El orgullo de defender lo que uno es. (Entrevista personal L.Ñ., febrero 2010)

Esta visibilidad y reconocimiento por los cuales estas jóvenes tenían que pelear en el aula hoy en día ya es un piso ganado. Los municipios, las escuelas y los académicos ya no pueden hacer uso y desuso de temas y acontecimientos que atañen a los pueblos originarios sin la participación o el consentimiento de los integrantes de aquellos pueblos. Recuerdo que en una oportunidad, en el año 2015, ciertos militantes de la región estaban ofendidos porque la municipalidad de Trelew había decido colocar, sin el consentimiento de las comunidades, unas estatuas de madera en representación de los pueblos originarios y del pueblo galés, en la plaza principal de aquella ciudad. El problema fue que, además de no pedir permiso, estas estatuas representaban a los indígenas de manera "sumisa y estereotipada": “PPor qué nos tienen que hacer de rodillas como sumisos? A la parejita de galeses la hicieron sentaditos de la mano y a nosotros de rodillas en un fuego. Y para colmo ni avisaron que las habían hecho" (Entrevista personal, E.A., noviembre 2015).

Frente a esto, algunas lof elevaron una carta y lograron sacar la estatua de la plaza central, y así mostraron no solo que es necesaria la consulta y participación previa de las comunidades en temas que las involucren, sino que son ellas quienes deciden las formas en que van a ser presentadas frente a la sociedad en general.

En esta toma de control sobre los modos de su visibilidad, los mapuche-tehuelche se propusieron colectivamente asumir los roles de organizadores y protagonistas de todos los eventos oficiales que estuvieran centrados en una historia que los involucra, particularmente aquellos que conmemoran ciertas fechas. El resultado de estas luchas locales fue que fueran invitados a dar charlas o a participar en los actos públicos como los transmisores, narradores y productores autorizados de sus conocimientos. Estos eventos les permiten, además del acceso y control sobre la producción y las formas 
de narrar sus saberes, revertir la imagen sobre el tehuelche extinguido y el mapuche ruralizado.

La legitimidad para ocupar estos lugares de autoridad la obtuvieron a partir de numerosas intervenciones, muchas veces imperceptibles, en las que integrantes de las lof que se iban organizando decidían pedir el turno para hablar o para representar algún aspecto de su propia cultura en algún escenario público. En este proceso de varios años, ellos fueron ganando espacios municipales y provinciales de enunciación, así como un creciente reconocimiento de su exclusividad como enunciadores de sí mismos.

En el año 2015, en uno de los actos del aniversario de la ciudad de Puerto Madryn, una integrante de la comunidad Pu fotum mapu pintó un dibujo tehuelche sobre una piedra laja que fue colocada luego en Punta Cuevas - zona en la que se realiza el acto simbólico del desembarco galés y el posterior encuentro con los pueblos originarios-. Este dibujo tenía un significado particular para ella y su lof, puesto que en él representaba el camino que emprende un "tehuelche una vez que encuentra su muerte" (Discurso público, M. N.., junio 2015).

A simple vista, aquel dibujo parecía ser otra de las manifestaciones multiculturales, "folklóricas" y tolerables en el marco del aniversario de la ciudad. Sin embargo, es recordado por la comunidad como una práctica política y transformadora: en aquel dibujo se escondían significados sociales de fondo. Por un lado, una integrante de una lof urbana toma la palabra como tal y se presenta como heredera de los conocimientos de sus ancestros. Por el otro, la elección de un tema tan "delicado" y profundo como los sentidos que sus antepasados daban a la vida y la muerte representaba, frente a la audiencia, a un pueblo fortalecido espiritual y afectivamente. De este modo, y tanto al tomar la palabra como al transmitir los conocimientos, esta joven estaba recordando a la sociedad de Madryn que ella era parte de un "nosotros" en continuidad - y junto- con sus abuelo/as, bisabuelos/as, tal como unos años antes solo lo podían hacer los galeses: "una fecha muy especial, donde recordamos a nuestros antepasados y el significado es tan profundo, representando a aquellos que ya no están, y por eso lo hacemos en un día como hoy" (Discurso público M.Ñ., junio 2015).

Esta presentación adquirió un valor político específico y coyuntural en el marco de sus militancias por la reivindicación de su pueblo. El hecho de dibujar sobre una piedra fue en sí mismo un modo de materializar y fijar su posicionamiento, pero al convertirla en un monumento oficial - con una placa explicativa del dibujo - en el sitio Punta Cuevas, constituyó un acto de resistencia por parte de la comunidad. Esto último debido a que esta zona es un sitio declarado patrimonio histórico y cultural por la municipalidad de Puerto Madryn, por ser considerado como "el primer asentamiento galés" (Gavirati, Coronato y Jones 2006). Colocar un dibujo tehuelche, realizado por alguien que se autoidentifica como mapuche-tehuelche, en un espacio que histórica y oficialmente parecería corresponder a "los galeses", fue una decisión política. Con este gesto, ellos monumentalizaron la preexistencia de su pueblo con respecto a la inmigración galesa y al Estado, así como, en el trazo de la artista, fijaron en el espacio público su principal premisa: los mapuche-tehuelche están vivos y hacen uso de sus privilegios de ser los agentes más autorizados para narrar su historia, incluso en contraste con aquella que los invisibilizó.

Entiendo, para finalizar, que estos lugares de autoridad que fueron performando en sus intervenciones públicas también se volvieron una práctica fundamental para expresar y poner en valor los sentimientos que iban emergiendo en sus procesos de búsqueda personal en torno a su identidad en la actualidad y en la ciudad. 


\section{Impugnación de los criterios de autenticidad}

Este artículo tuvo como propósito mostrar cómo los mapuche-tehuelche de la costa y valle de Chubut identificaron sus propios objetos de reclamo y, al hacerlo, constituyeron sus subjetividades personales y colectivas en la doble pertenencia. Ya es un piso ganado el hecho de que sea impensable la zona sin la presencia y visibilidad de comunidades, organizaciones y personas que se autorreconocen en esa doble adscripción. A lo largo de los años, sus luchas han habilitado un escenario de presencias en el cual los reclamos, los posicionamientos públicos y las formas posibles de ser audibles y visibles como mapuche-tehuelche ya no pueden ser deslegitimadas por los criterios hegemónicos de definición de alteridades.

Frente a las construcciones multiculturales del indígena de ciertos discursos históricos y científicos, la pelea principal fue y sigue siendo el reconocimiento de sus presencias como agentes de su propia historia, y como sujetos de derecho para el cumplimiento y la ampliación de sus derechos como pertenecientes a los pueblos originarios. Con este fin, primero tuvieron que desidentificarse con ciertos lugares disponibles para habilitarlos de otras maneras o crear nuevas moradas de apego y de resistencia. En estas desidentificaciones, el lugar dispuesto para el tehuelche ha sido el más ocupado, resignificado y transformado por la lucha indígena en la región, puesto que, a diferencia de los lugares de estigma del mapuche, este no dejaba margen para la existencia, y muchos menos para la agencia. Presuponiendo sus pertenencias al pueblo mapuche, pero identificándose marcadamente como "tehuelches viviendo en la ciudad", los mapuche-tehuelche de la costa y el valle impugnaron las construcciones hegemónicas que sostenían que el indígena era parte de un pasado inmemorial o un ser en extinción.

Así, transitando este camino de luchas, la doble adscripción operó como una puesta en foco alternativa y significativa sobre los procesos históricos hegemónicos. Los mapuchetehuelche dejaron de ser definidos por difusión de rasgos culturales o enfrentamientos de pueblos (entendidos como naciones o confederaciones indígenas), para ser comprendidos por medio de las interrelaciones entre ellos. Al sostener que sus antepasados son tanto mapuche como tehuelche, pueden reescribir la historia desde las agencias políticas de sus grupos parentales, de sus conexiones y desconexiones en las formas cambiantes de negociar el "ser juntos" (Massey, 2005) en contextos de avasallamiento y dominación. En este camino, pelear el control sobre los usos del pasado y sobre la producción de conocimientos les permitió reconfigurar el escenario hegemónico de alteridad en el que el tehuelche extinto y el mapuche extranjero no tenían lugar como agentes políticos o sujetos de derecho.

Ni extinguidos ni invasores los mapuche-tehuelche habitan la ciudad y la ciudad es parte de su territorio ancestral. Esta es la idea que construyeron en actos muy simples, en intervenciones públicas muy sencillas y por medio de desplazamientos de sentido muy sutiles. Así refundaron sus pasados como pueblo y recuperaron formas de ser y comprender el mundo entendidas colectivamente como propias. Al unir lo que no debía ser unido en una doble pertenencia, conjugaron historia, territorio y política de modos incómodos para el poder local.

\section{Sobre la Autora}

Licenciada en Ciencias Antropológicas de la Universidad Nacional de Buenos Aires. Doctora en Antropología de la Facultad de Filosofía y Letras, de la Universidad Nacional de Buenos Aires. Profesora de la materia de Antropología Sociocultural de la carrera de Historia de la Universidad Nacional del Comahue. 


\section{Q Referencias bibliográficas}

"Alonso, A. M. (1994). The politics of space, time and substance: state formation, nationalism, and ethnicity. Annual Review of Anthropology, 23, 379-405.

" Bartolomé, M. A. (2003). Los pobladores del “Desierto”. Genocidio, etnocidio y etnogénesis en la Argentina. Cuadernos de Antropología Social, 17, 162-189.

"Bompadre, J. M. (2013). Procesos de comunalización contemporánea de pueblos originarios en contextos urbanos y rurales de la provincia de Córdoba. En X Reunión de Antropología del Mercosur, Universidad Nacional de Córdoba, Córdoba, Argentina

" Briggs, C. (1986). Learning how to ask: A sociolinguistic appraisal of the role of the interview in social science research. Cambridge: Cambridge University Press.

» Briones, C. (1998). (Meta) cultura del Estado-nación y estado de la (meta) cultura: Repensando las identidades indígenas y antropológicas en tiempos de post-estatalidad. Série Antropologia, 244, 1-56.

"Briones, C. (2005). Formaciones de alteridad: contextos globales, procesos nacionales y provinciales. En C. Briones (Ed.), Cartografías argentinas. Políticas indigenistas y formaciones provinciales de alteridad (pp. 9-36). Buenos Aires: Antropofagia.

" Briones, C. y Ramos, A. (2010). Replanteos teóricos sobre las acciones indígenas de reivindicación y protesta: Aprendizajes desde las prácticas de reclamo y organización mapuche-tehuelche en Chubut. En G. Gordillo y S. Hirsch (Comps.), Movilizaciones indígenas e identidades en disputa en la Argentina: historias de invisibilización y reemergencia (pp. 29-78). Buenos Aires: La Crujía.

»Casamiquela, R. M. (1987). Toponimia Indígena del Chubut. Rawson: Gobierno de la Provincia del Chubut.

"Ciccone, F. y Hirsch, S. (2011). Representaciones culturales y lingüísticas en el resurgimiento identitario de los tapietes. En G. Gordillo y S. Hirsch (Eds.), Movilizaciones indígenas e identidades en disputa en la Argentina (pp. 123-146). Buenos Aires: La Crujía.

»Coronato, F., Gavirati, M., y Jones, N. (2006). Los galeses en la Patagonia: la conformación de un singular modelo político, económico y cultural. En Los galeses en la Patagonia II: selección de trabajos del Segundo Foro Internacional sobre los Galeses en la Patagonia, (pp, 167-195). Carmen de Patagones: Fundación Ameghino.

" Cox, G. E. (1863). Viaje en las regiones septentrionales de la Patagonia, 1862-1863. Buenos Aires: El Elefante Blanco.

»Das, V. (1995). Critical events: An anthropological perspective on contemporary India. Delhi, India: Oxford University Press.

»Delrio, W. (2010). Del no-evento al genocidio. Pueblos originarios y políticas de estado en Argentina. Eadem Utraque Europa, 6(10-11), 219-254.

» Escalada, F. A. (1949). El complejo "tehuelche": estudios de etnografía patagónica. Buenos Aires: Coni.

"Escobar, A. (2007). El giro decolonial: reflexiones para una diversidad epistémica más allá del capitalismo global. Bogotá: Siglo del Hombre.

"Escolar, D. (2007). Los dones étnicos de la Nación. Identidades huarpe y modos de producción de soberanía en Argentina. Buenos Aires: Prometeo.

»Escolar, D. (2017). Gendarmería. Los límites de la obediencia. Buenos Aires: San Benito. 
» Falkner, T. y Musters, G. (1911). Descripción de la Patagonia, Vol. 1. Buenos Aires: Coni.

» García, A. y Valverde, S. (2007). Políticas estatales y procesos de etnogénesis en el caso de poblaciones mapuche de Villa La Angostura, provincia de Neuquén, Argentina. Cuadernos de Antropología Social, 25, 111-132.

» Golluscio, L. (2006). El Pueblo Mapuche. Política de Pertenencia y Devenir. Buenos Aires: Biblos.

» Grossberg, L. (1992). We gotta get out of this place. Popular conservatism and postmodern culture. Nueva York: Routledge.

» Grossberg, L. (1996). Identity and Cultural Studies: Is That All There Is? En S. Hall y P. Du Gay (Eds.), Questions of Cultural Identity (pp. 87-107). Londres: Sage.

» Hale, C. (2004). Rethinking Indigenous Politics in the Era of the 'Indio Permitido'. NACLA Report on the Americas, 38,16-21.

» Hall, S. (2010). La cuestión multicultural. En Sin garantías. Trayectorias y problemáticas en estudios culturales (pp. 583-618). Popayán, Lima y Quito: Envión Editores-IEP-Instituto Pensar-Universidad Andina Simón Bolívar.

» Harrington, T. (1944). Nombres indios y galeses de la toponimia patagónica. Revista Geográfica Americana, 21(127), 236-238.

» Krotz, E. (2018). Antropología: conocimiento y política. Encartes Antropológicos, 1(1), 67-83.

» Kropff, L. (2008). Construcciones de aboriginalidad, edad y politicidad entre jóvenes mapuche (tesis de doctorado). Universidad de Buenos Aires, Facultad de Filosofía y Letras, Buenos Aires, Argentina.

" Lazzari, A. (2010). Autonomy in Apparitions: Phantom Indian, Selves and Freedom (tesis de doctorado). Columbia University, Nueva York, Estados Unidos.

» Leyva, X. y Speed, S. (2015). Hacia la investigación descolonizada: nuestra experiencia de co-labor. En X. Leyva, Alonso, R. A. Hernández, A. Escobar, A. Köhler. (Eds.), Prácticas otras de conocimiento(s): entre crisis, entre guerras, 3 vol. (pp. 451-480). San Cristóbal de Las Casas: Cooperativa Retos.

» Massey, D. (2005). Throwntogetherness: The Politics of the Event of Place. En D. Massey, For Space (pp. 149-162). Londres: Sage.

» Nahuelquir, F., Sabatella, M. E. y Stella, V. (2011). Analizando los “no saberes”. Reflexiones de procesos de memoria-olvido a partir de experiencias situadas de agenciamiento indígena. Identidades, 1, 21-47.

》Quijano, A. (2011). Colonialidad del poder y clasificación social. Contextualizaciones Latinoamericanas, 5.1-32. Recuperado de http://revistascientificas.udg.mx/index.php/CL/ article/viewFile/2836/2574

»Ramos, A. (2010). Los pliegues del linaje. Memorias y políticas mapuches-tehuelches en contextos de desplazamiento. Buenos Aires: Eudeba.

"Ramos, A. (2017). El asesinato de Rafael Nahuel y la represión en la Patagonia. Ser pobre, joven y mapuche. En Gemas Memoria. Ensayos y reflexiones. Recuperado de https:// gemasmemoria.com/2017/11/30/el-asesinato-de-rafael-nahuel-y-la-represion-en-la-patagonia-ser-pobre-joven-y-mapuche/

»Ramos, A. y W. Delrio. (2005). Trayectorias de oposición. Los mapuches y tehuelches frente a la hegemonía en Chubut. En C. Briones (ed.), Cartografías argentinas: políticas indígenas y formaciones provinciales de alteridad (79-118). Buenos Aires: Antropofagia.

»Ramos, A. y Stella, V. (2017). Una reflexión política sobre los usos y los sentidos de "ser mapuche" y "ser tehuelche". Identidades, 5, 133-156. 
» Rapapport, J. (2005). Cumbe Renaciente. Una Historia Etnográfica Andina. Bogotá: Universidad del Cauca.

" Rappaport, J. (2007). Más allá de la escritura: la epistemología de la etnografía en colaboración. Revista Colombiana de Antropología, 43. 197-229.

»Restrepo, E. (2004). Biopolítica y alteridad: Dilemas de la etnización de las Colombias Negras. En E. Restrepo y A. Rojas (Eds.), Conflicto e (in)visibilidad. Retos en los estudios de la gente negra en Colombia (pp. 271-301). Popayán: Editorial Universidad del Cauca.

"Rodríguez, M. (2010). De la "extinción" a la autoafirmación: procesos de visibilización de la Comunidad Tehuelche Camusu Aike (provincia de Santa Cruz, Argentina) (tesis de doctorado). Georgetown University, Nueva York, Estados Unidos.

"Stella, V. (2014). Subjetividades mapuche-tehuelche. Un análisis situado en el mapa hegemónico de la localidad de Puerto Madryn (Chubut). Viedma: Universidad Nacional de Río Negro.

"Stella, V. (2017). Un análisis sobre la pluriculturalidad en la costa y valle de Chubut. (En) clave Comahue. Revista Patagónica de Estudios Sociales, 22, 253-270.

"Stella, V. (2018). Relacionalidad, memoria y subjetividades políticas. Un análisis sobre los sentidos de pertenencia mapuche-tehuelche en la costa y valle de la provincia de Chubut (tesis de doctorado). Facultad de Filosofía y Letras, Universidad Nacional de Buenos Aires, Buenos Aires, Argentina.

"Walsh, C. (2007). ¿ Son posibles unas ciencias sociales/culturales otras? Reflexiones en torno a las epistemologías decoloniales. Nómadas 26: 102-113

\section{Otras fuentes consultadas}

»Dirección General de Estadísticas y Censos (DGEyC). (2019). Población indígena u originaria por pueblo. Total Provincia Año 2010. Subsecretaría de Modernización del Estado. Recuperado de https://www.estadistica.chubut.gov.ar/home/index.php?option=com_c ontent\&view $=$ article\&id $=606 \& \mid$ temid $=498$

» Ministro de Chubut acusó a los mapuches del grupo RAM: Son terroristas. (12 de enero de 2017) Diario Río Negro. Recuperado de http://www.rionegro.com.ar/region/son-terroristas--ministro-de-chubut-acuso-a-los-mapuches-del-grupo-ram-GG1998967

» Hanglin, R. (16 de septiembre de 2014). Quiénes son los mapuches. Diario La Nación. Recuperado de https://www.lanacion.com.ar/1727466-historia-mapuche

» Huircapan, D. (7 de julio de 2015). La tierra es el hecho fundamental por el que pelean todos los pueblos originarios. Agencia Paco Urondo. Recuperado de http://www.agenciapacourondo.com.ar/mas-informacion/la-tierra-es-el-hecho-fundamental-por-el-quepelean-todos-los-pueblos-originarios 